\title{
Identification of amino acid residues of Salmonella SlyA that are critical for transcriptional regulation
}

\author{
Correspondence \\ Nobuhiko Okada \\ okadan@pharm.kitasato-u.ac.jp
}

Received 28 June 2006

Revised 14 September 2006

Accepted 20 October 2006

\author{
Nobuhiko Okada, ${ }^{1}$ Yorie Oi, ${ }^{1}$ Mayuko Takeda-Shitaka, ${ }^{2}$ Kazuhiko Kanou, ${ }^{2}$ \\ Hideaki Umeyama, ${ }^{2}$ Takeshi Haneda, ${ }^{1}$ Tsuyoshi Miki, ${ }^{1}$ Sachiko Hosoya ${ }^{1}$ \\ and Hirofumi Danbara ${ }^{1}$
${ }^{1}$ Department of Microbiology, School of Pharmaceutical Sciences, Kitasato University, Tokyo 108-8641, Japan
${ }^{2}$ Department of Biomolecular Design, School of Pharmaceutical Sciences, Kitasato University, \\ Tokyo 108-8641, Japan
}

\section{INTRODUCTION}

Salmonella enterica, a facultative intracellular pathogen, can replicate within macrophages. The intracellular survival of $S$. enterica serovar Typhimurium requires a number of virulence-associated proteins encoded in Salmonella pathogenicity island 2 (SPI-2) on the bacterial chromosome (Cirillo et al., 1998; Hensel, 2000; Ochman et al., 1996; Shea et al., 1996). SPI-2 encodes a two-component regulatory system, structural components of a type III secretion system (TTSS), effector proteins and chaperones, which mediate the secretion of the effectors (Cirillo et al., 1998; Hensel et al., 1998; Ochman et al., 1996; Shea et al., 1996). In infected macrophages, Salmonella replicates within a membranebound compartment (Salmonella-containing vacuole, SCV) inside the host cells (Steele-Mortimer et al., 2002). Intracellular activation of SPI-2 function is essential for

Abbreviations: DSS, disuccimidyl suberate; SCV, Salmonella-containing vacuole; Sif, Salmonella-induced filament; SPI-2, Salmonella pathogenicity island 2; TTSS, type III secretion system.
SCV maturation along the phagolysosomal fusion pathway, which is responsible for the inhibition of bacterial degradation in phagolysosomes. The SPI-2 TTSS functions to export effector proteins across the SCV membrane and into the cytosol of host cells, resulting in the prevention of the recruitment of NADPH oxidase to the SCV (Gallois et al., 2001; Vazquez-Torres et al., 2000), as well as leading to the rearrangement of cellular microfilaments (Meresse et al., 2001; Miao et al., 2002) and microtubule networks (Brumell et al., 2002; Guignot et al., 2004). Remodelling of the host cell cytoskeleton is thought to be involved in maintaining the integrity of the SCV membrane and directing SCV traffic. In Salmonella-infected epithelial cells, the SCV forms long filamentous structures referred to as Salmonellainduced filaments (Sifs), which are elongated tubules that appear to extend from the SCV membrane along the host cell microtubules (Guignot et al., 2004).

The expression of SPI-2 TTSS structural components and the associated secreted effectors is induced specifically inside host cells (Cirillo et al., 1998; Shea et al., 1996; Valdivia \& 
Falkow, 1997), as well as under in vitro conditions that mimic the intracellular environment of the SCV, which include low osmolarity (Garmendia et al., 2003; Lee et al., 2000), calcium limitation (Garmendia et al., 2003), phosphate limitation (Deiwick et al., 1999) and iron limitation (Zaharik et al., 2002). The induction of SPI-2 genes in response to these stimuli is dependent on SsrA (also referred to as SpiR)/SsrB, a two-component regulatory system encoded within the SPI-2 region. SsrA is the putative cognate sensor kinase for $\mathrm{SsrB}$, and $\mathrm{SsrB}$ is the response regulator (Ochman et al., 1996; Worley et al., 2000). Once activated, SsrB induces the expression of genes located both inside and outside SPI-2 by the direct binding of target gene promoters (Feng et al., 2004; Garmendia et al., 2003; Miao et al., 2002). Upstream signals that activate SPI-2 gene expression are dependent on two other two-component regulatory systems, OmpR/EnvZ (Feng et al., 2003, 2004; Lee et al., 2000; Worley et al., 2000) and PhoP/PhoQ (Bijlsma \& Groisman, 2005; Deiwick et al., 1999). OmpR binds to both $s s r A$ and $s s r B$ promoters in vitro (Feng et al., 2003, 2004; Lee et al., 2000), and PhoP is directly involved in $s s r B$ transcription and the protein levels of SsrA posttranscriptionally (Bijlsma \& Groisman, 2005). In addition to these regulatory systems, it has been reported that SlyA, a virulence-associated transcriptional regulator, controls the expression of ssrAB in vivo (Feng et al., 2004; Linehan et al., 2005; Navarre et al., 2005). However, it has not yet been determined whether SlyA controls the $s s r A B$ transcript as a direct or an indirect effect.

The Salmonella slyA gene is implicated in virulence, survival in mouse macrophages, resistance to oxidative stress and resistance to antimicrobial peptides (Buchmeier et al., 1997; Daniels et al., 1996; Kaneko et al., 2002; Libby et al., 1994; Navarre et al., 2005; Shi et al., 2004; Watson et al., 1999). SlyA regulates the expression of a large number of genes during the stationary phase and also in the intracellular environment of host cells (Buchmeier et al., 1997; Daniels et al., 1996). Recently, transcriptome and proteome analyses have identified a large number of SlyAdependent (activated and repressed) genes belonging to the SlyA regulon (Navarre et al., 2005; Spory et al., 2002; Stapleton et al., 2002). Interestingly, several of these SlyAactivated genes were also controlled by the PhoP/PhoQ twocomponent regulatory system, including those genes required for virulence and resistance to antimicrobial peptides (Navarre et al., 2005). In addition, slyA itself is activated under low- $\mathrm{Mg}^{2+}$ conditions by the PhoP protein, which binds directly to the slyA promoter region (Norte et al., 2003; Shi et al., 2004).

SlyA is known as a member of the MarR/SlyA family of transcription regulators, more than 130 of which have been identified thus far in bacteria and archaea (Thomson et al., 1997; Wu et al., 2003). Within this family, SlyA is closely related to RovA from Yersinia, Rap from Serratia marcescens and Hor from Erwinia carotovora. In addition, it is more distantly related to MarR, EmrR, HpaR and HpcR from
Escherichia coli; MexR from Pseudomonas aeruginosa; PecS from Erwinia chrysanthemi; SlyA-Ef from Enterococcus faecalis; and $\mathrm{Hpr}$ and $\mathrm{ScoC}$ from Bacillus subtilis. Moreover, it has been shown to be related to several other regulatory proteins. These regulatory proteins control the expression of resistance to multiple antibiotics, organic solvents, agents that induce oxidative stress, and virulence factors (Alekshun \& Levy, 1997). This diverse group of MarR homologues is very similar with respect to protein structure; the protein forms a dimer and contains a wingedhelix DNA-binding motif (Alekshun et al., 2001; De Silva et al., 2005; Hong et al., 2005; Lim et al., 2002; Liu et al., 2001; Wu et al., 2003). In these regulatory proteins, the helix-turn-helix motif is followed by a wing composed of two antiparallel $\beta$-strands. Therefore, MarR/SlyA family proteins consist of two functional domains, one for protein dimerization and one for DNA interaction.

It has been demonstrated previously that the dimer form of SlyA interacts with the DNA and recognizes a palindromic DNA structure (Stapleton et al., 2002). The 12 bp consensus sequence, TTAGCAAGCTAA, is located in the slyA promoter, and has been identified as the SlyA-binding site, which is involved in the autoregulation of the slyA gene (Stapleton et al., 2002). In several SlyA-regulated genes, DNA sequences (TTTAGTTTTTGTCTTAA, located in the ugtL promoter; TTTGGAATGTAA, located in the pagC promoter; and TTAGCTGTTAA, located in the mig-14 promoter) have been identified as SlyA-specific binding sites by DNase I protection assay (Navarre et al., 2005; Shi et al., 2004). Thus, it is likely that the SlyA homodimer binds preferentially at the inverted repeat with a core TTAG motif.

More recently, it was demonstrated that the inability of a Salmonella slyA mutant strain to survive within macrophages was partly due to the reduced expression of SPI-2 genes (Linehan et al., 2005). Although the mechanism by which SlyA controls $s s r A B$ transcription remains unknown, it has been suggested that the SlyA protein promotes SPI-2 function via the SsrA/SsrB two-component regulatory system (Feng et al., 2004; Linehan et al., 2005; Navarre et al., 2005). Here, we report that the transcription of the $s s r A$ gene and the expression of SPI-2 function in vivo both require the slyA regulatory gene. We show that the SlyA protein binds directly to the $s s r A$ promoter. In order to more fully understand the molecular mechanism involved in $s s r A$ gene expression in Salmonella, we constructed a structural model of the SlyA dimer in the complex with DNA. Using the predicted structure of the SlyA-DNA complex, we identified several specific residues in SlyA that are critical for DNA binding activity and for dimer formation. The importance of these residues in the functional domains of SlyA was confirmed by site-directed mutagenesis. In vivo and in vitro analyses of the point-mutated SlyA proteins revealed that the amino acid residues of SlyA involved in the interaction with DNA and in dimerization are critical for the transcriptional activation of the $s s r A$ gene. 


\section{METHODS}

Bacterial strains, plasmids and growth conditions. The bacterial strains and plasmids used in this study are listed in Table 1. E. coli and Salmonella strains were grown in Luria-Bertani (LB) broth or on LB agar under conditions for selection for resistance to ampicillin $\left(100 \mu \mathrm{g} \mathrm{ml}^{-1}\right)$, kanamycin $\left(25 \mu \mathrm{g} \mathrm{ml}^{-1}\right)$ and nalidixic acid $\left(50 \mu \mathrm{g} \mathrm{ml}^{-1}\right)$, as appropriate.

Plasmid construction and site-directed mutagenesis. The sly gene of $S$. enterica serovar Typhimurium is translated from a TTG codon and encodes a 144 aa protein (Kawakami et al., 1999). A DNA fragment containing the $s l y A$ gene was amplified by PCR from the genomic DNA of S. enterica serovar Typhimurium strain SH100 using primers slyA-N1 (5'-GGCTCGAGTTGGAATCGCCACTAGGTTCTG-3' ${ }^{\prime}$ and slyA-N2 (5'-GGCTGCAGATCGTGAGAGTGCAAATTCCAA-3'). The 445 bp PCR product was digested with $X h o I$ and PstI and ligated into the same site of the expression vector, pBAD-HisA (Invitrogen), thereby generating pBAD-slyA. The SlyA point mutants were constructed by site-directed mutagenesis using pBAD-slyA as a template and the respective oligonucleotide primers, and by using the GeneTailer site-directed mutagenesis system (Invitrogen) according to the manufacturer's instructions. The mutated plasmids were transformed into E. coli $\mathrm{DH} 5 \alpha-\mathrm{T} 1^{\mathrm{R}}$ competent cells (Invitrogen), and the presence of the respective mutation was confirmed by DNA sequencing.

For the complementation assays, the plasmid pMW-slyA was constructed by inserting the XhoI-HindIII fragment containing the slyA gene from pBAD-slyA into the Sall-HindIII sites of pMW119 (Nippon Gene).

Mutant construction. A nonpolar mutant of $s l y A$ was constructed by insertion mutagenesis and allele exchange using the temperatureand sucrose-sensitive suicide vector pCACTUS as described previously (Miki et al., 2004). A disruption of the slyA gene was created by insertion of the SmaI-digested $\mathrm{Km}^{\mathrm{r}}$-encoding gene (kan) cassette from plasmid pUC18K (Menard et al., 1993), which does not affect transcription of downstream genes, into the RsaI site in the coding region of slyA. The disrupted genes were then subcloned using Sall and SphI into the similarly digested pCACTUS, and the resulting plasmid was introduced into strain $\mathrm{SH} 100$ by electroporation for allele-exchange mutagenesis, thereby generating sly $A$ insertion mutant strain SH110 (slyA::kan). Chromosomal mutations were verified by PCR analysis.

Salmonella strains SH112 and SH113 were constructed by P22 phage transduction of an $s s r A:$ :kan mutation from a derivative of strain ATCC 14028s (Gotoh et al., 2003) and a $\Delta s s a V:$ : cat mutation from strain TM114, a derivative of strain SL1344 (Miki et al., 2004), respectively, to the wild-type strain $\mathrm{SH} 100$.

To construct a transcriptional fusion of the $s s r A$ promoter region to the promoterless lac $Z$ gene in the integrational plasmid $\mathrm{pLD}-\mathrm{lacZ} \Omega$ (Miki et al., 2004), the DNA fragment containing the $s s r A$ promoter region was amplified by PCR using primers ssrA-Pro (5'-GGGGTCGACCTGTGAAATTCGCTCACAACC-3') and ssrA-RV (5'-G $\overline{\text { GGG- }}$ GATCCTCAGTCGCTAATGAGCATTGA- $\left.3^{\prime}\right)$. The PCR product digested with SalI and BamHI was ligated into the same sites of $\mathrm{pLD}-\mathrm{lac} Z \Omega$, thus producing $\mathrm{pLD}$-ssrAZ. The resulting plasmids were

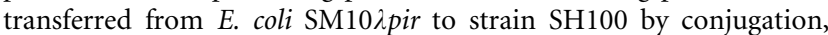
generating strain $\mathrm{SH} 122$.

Expression and purification of the SlyA protein. For the expression of recombinant SlyA protein, plasmid pBAD-slyA was introduced into E. coli strain LMG194 (Invitrogen) and was expressed according to the manufacturer's instructions. N-terminal His $_{6}$-tagged SlyA (His 6 -SlyA) fusion protein was purified by affinity chromatography on Ni-NTA agarose (Qiagen).

SDS-PAGE and Western blot analysis. The protein samples were separated by SDS-PAGE and transferred to PVDF membranes (Immobilon, Millipore) for immunoblotting. Western blot analysis was carried out as described previously (Miki et al., 2004). The blots were incubated with anti-Penta.His antibody (1:1000, Qiagen), and anti-mouse secondary antibody conjugated to alkaline phosphatase (Sigma) was used at a 1:10000 dilution.

Table 1. Bacterial strains and plasmids

\begin{tabular}{|c|c|c|}
\hline Strain or plasmid & Relevant characteristics & Reference or source \\
\hline \multicolumn{3}{|l|}{ Salmonella } \\
\hline SH100 & Serovar Typhimurium, wild-type, $\mathrm{Nal}^{\mathrm{r}}$ & Gotoh et al. (2003) \\
\hline SH110 & slyA:: kan in $\mathrm{SH} 100, \mathrm{Km}^{\mathrm{r}}$ & This study \\
\hline SH112 & ssrA: $k a n\left(\mathrm{Km}^{\mathrm{r}}\right)$ in $\mathrm{SH} 100$ & This study \\
\hline SH113 & $\Delta s s a V:$ : cat $\left(\mathrm{Cm}^{\mathrm{r}}\right)$ in $\mathrm{SH} 100$ & This study \\
\hline SH122 & ssrA: : lacZ $\left(\mathrm{Spc}^{\mathrm{r}}\right)$ in $\mathrm{SH} 110$ & This study \\
\hline \multicolumn{3}{|l|}{ E. coli } \\
\hline DH $5 \alpha$ & supE44 $\Delta l a c U 169$ ( $\phi 80$ lacZAM15) hsdR17 recA1 endA1 gyrA96 thi-1 relA1 & Gibco-BRL \\
\hline LMG194 & DlacX74 galE thi rpsL $\Delta$ phoA $\Delta$ ara714 leu::Tn10 & Invitrogen \\
\hline SM10ipir & thi-1 thr leu tonA lacY supE recA:: RP4-2-Tc:: Mu $\lambda$ pir & Simon et al. (1983) \\
\hline \multicolumn{3}{|l|}{ Plasmids } \\
\hline pCACTUS & Temperature- and sucrose-sensitive suicide vector, $\mathrm{Cm}^{\mathrm{r}}$ & Miki et al. (2004) \\
\hline pBAD-HisA & Expression vector for $\mathrm{His}_{6}$ fusion protein & Invitrogen \\
\hline pBAD-slyA & pBAD-HisA containing slyA gene & This study \\
\hline pMW119 & pSC101-based low-copy-number plasmid, $\mathrm{Amp}^{\mathrm{r}}$ & Nippon Gene \\
\hline pMW-slyA & pMW119 containing slyA gene & This study \\
\hline $\mathrm{pLD}-\mathrm{lac} Z \Omega$ & Integrational plasmid with promoterless lac $Z$ gene, $\mathrm{Spe}^{\mathrm{r}}$ & Miki et al. (2004) \\
\hline pLD-ssrAZ & $s s r A::$ lac $Z$ operon fusion in $\mathrm{pLD}-l a c Z \Omega$ & This study \\
\hline
\end{tabular}


DNA-binding assays. For the binding assays of the immobilized SlyA protein to purified DNA, His $_{6}$-SlyA protein was immobilized on Dynabeads M-450 Goat anti-Mouse IgG (Dynal) by antiPenta.His antibody as described previously (Tobe et al., 1996). Defined PCR fragments carrying different portions of the ssrA promoter region were incubated with Dynabeads-SlyA in $50 \mu$ binding buffer containing $10 \mathrm{mM}$ Tris/ $\mathrm{HCl}(\mathrm{pH} 7.9), 5 \%$ (w/v) glycerol, $1 \mathrm{mM}$ EDTA, $1 \mathrm{mM}$ DTT and $400 \mathrm{mM} \mathrm{NaCl}$ at $4{ }^{\circ} \mathrm{C}$ for $60 \mathrm{~min}$. After the Dynabeads were captured on Dynal MCP (Dynal), the supernatant containing unbound DNA was transferred to new tubes. The Dynabeads were then washed three times in binding buffer. Bound DNA was released from the Dynabeads-SlyA complex by incubation in high-salt buffer containing $10 \mathrm{mM}$ Tris/ $\mathrm{HCl}$ (pH 7.9), $5 \%$ glycerol, $1 \mathrm{mM}$ EDTA, $1 \mathrm{mM}$ DTT and $2 \mathrm{M} \mathrm{NaCl}$. After precipitation by the addition of ethanol, the DNAs were resuspended in $10 \mu \mathrm{TE}$ buffer, and then the samples were analysed by $1.5 \%$ agarose gel electrophoresis. The PCR fragments used for the assays were amplified with the following primers: ssrA-P1 (5'-CATTCGGATTTTCCGATAAATTCAC-3'), ssrA-P2 (5'-ACGATGTTTTTACATCGCCATCTTA - $\left.3^{\prime}\right)$, ssrA-1 (5'-AATTTGCTCAATCTCAAGAATAGCG-3') and ssrA-R1 (5'-CGTTGATTGCTTAGTACAATATTCATCTCG-3'). The PCR products were purified with a MinElute PCR Purification kit (Qiagen).

For the DNA retardation assays, the binding of SlyA to PCR fragments was carried out in a $20 \mu \mathrm{l}$ reaction mixture containing purified SlyA protein and $1 \mu \mathrm{g}$ of each DNA. The reaction buffer contained $10 \mathrm{mM}$ Tris/ $\mathrm{HCl}$ (pH 7.5), 1 mM EDTA, $50 \mathrm{mM} \mathrm{NaCl}, 50 \mathrm{mM} \mathrm{MgCl}_{2}, 5 \mathrm{mM}$ DTT and $5 \%$ glycerol. The reaction mixtures were incubated for $15 \mathrm{~min}$ at room temperature and were subsequently loaded onto $4 \%$ polyacrylamide gels, which were run in $0.5 \%$ TBE and stained with ethidium bromide.

Model of SlyA structure. The model structure of the SlyA-DNA complex was constructed based on homology modelling methods. Searches for reference proteins and sequence alignments were performed using SKE-CHIMERA (Takeda-Shitaka et al., 2005), which is a web user-interface system for protein structure predictions, through which the selection of reference proteins and sequence alignments are carried out by the analysis of abundant data generated by eight sequence search methods such as PSI-BLAST (Altschul et al., 1997). To assess the quality of homology modelling, the Critical Assessment of Techniques for Protein Structure Prediction (CASP6; http://predictioncenter.org/), a blind contest of protein structure prediction, is the most valuable experiment. In the most recent CASP6 held in 2004, the official assessment showed that the predictions using SKE-CHIMERA and FAMS (a fully automated homology modelling system) were successful in the homology modelling category (http://predictioncenter.org/casp6/meeting/presentations/ CASP6_Program.doc). Based on the alignment given by SKECHIMERA, FAMS Ligand\&Complex (FAMS that constructs proteinligand complex models based on the structure of the reference protein-ligand complex) successfully constructed a three-dimensional model structure (Ogata \& Umeyama, 2000; Takeda-Shitaka et al., 2004a, b, 2005, 2006). After the modelling was complete, the quality of the stereochemistry of the SlyA model was verified. In the model structure, no unfavourable contacts between the atoms and no unnatural chiral centres were observed, and there were no steric hindrances that prevented the close interaction of the two monomers in the homodimer. In the Ramachandran plot of the mainchain $\phi-\psi$ angles rendered by the program PROCHECK (Laskowski et al., 1993), almost all of the non-glycine residues were in the most favoured or allowed regions. Moreover, all of the $\omega$ angles were trans-planar. In this model structure, DNA from the Corynebacterium diphtheriae DtxR (C102D mutant)-DNA complex [Protein Database (PDB, Berman et al., 2000) ID code: 1F5T] was included in order to predict the SlyA-DNA interactions.
$\boldsymbol{\beta}$-Galactosidase assay. For $\beta$-galactosidase assay, S. enterica serovar Typhimurium strain SH122 with the plasmids pBAD-slyA and its derivatives expressing point mutations in SlyA were grown overnight at $37^{\circ} \mathrm{C}$ in LB medium with aeration and diluted at $1: 50$ into fresh $\mathrm{LB}$ broth and grown for $2 \mathrm{~h}$ under the same conditions. To induce the expression of the SlyA protein, arabinose was then added at a final concentration of $0.01 \%$ to each of the cultures, which were incubated for an additional $3 \mathrm{~h}$. The activity of the $s s r A$ promoter was estimated by measuring the $\beta$-galactosidase activity according to standard procedures with the substrate $o$-nitrophenyl $\beta$-D-galactoside (Miller, 1992). Samples were taken from each culture for Western blot analysis of $\mathrm{His}_{6}$-SlyA derivatives at the same time the enzyme assay was performed.

DSS cross-linking. Purified samples of $\mathrm{His}_{6}$-SlyA and its derivatives $(15 \mu \mathrm{g})$ were incubated with $100 \mu \mathrm{M}$ disuccimidyl suberate (DSS, Pierce) in a $100 \mu$ reaction mixture containing conjugation buffer (50 mM HEPES, pH 7.5, $200 \mathrm{mM} \mathrm{NaCl}$ ) at room temperature for $1 \mathrm{~h}$. The reaction was quenched by the addition of $1 \mathrm{M}$ Tris/ $\mathrm{HCl}, \mathrm{pH} \mathrm{8.0,} \mathrm{to} \mathrm{a} \mathrm{final} \mathrm{concentration} \mathrm{of} 25 \mathrm{mM}$, for $30 \mathrm{~min}$. The cross-linked samples (10 $\mu \mathrm{l}$ each) were analysed on $15 \%$ SDSPAGE gels and stained with Coomassie brilliant blue.

Cell cultures. HeLa cells were grown in minimal essential medium (MEM, Sigma) supplemented with $10 \%$ fetal bovine serum in the presence of gentamicin $\left(100 \mu \mathrm{g} \mathrm{ml}^{-1}\right)$ and kanamycin $\left(60 \mu \mathrm{g} \mathrm{ml}^{-1}\right)$ and were maintained in a humidified atmosphere containing $5 \%$ $\mathrm{CO}_{2}$ at $37^{\circ} \mathrm{C}$.

Bacterial infection of cultured cells. HeLa cells were infected with exponential-phase Salmonella strains as described previously (Miki et al., 2004). Cells were washed after $15 \mathrm{~min}$ exposure to Salmonella and subsequently incubated in medium containing gentamicin to kill extracellular bacteria. For SPI-2 phenotypic analysis of Salmonella-infected HeLa cells, the cells were fixed in $4 \%$ paraformaldehyde in PBS for $30 \mathrm{~min}$ at $4{ }^{\circ} \mathrm{C}$. After being washed three times in PBS, the fixed cells were permeabilized in $0.1 \%$ Triton X100 in PBS for $5 \mathrm{~min}$. For triple immunofluorescence staining, the samples were probed with the following: anti-LAMP-1 monoclonal antibody (H4A3, 1:1000, BD Pharmingen) and Alexa Fluor 488conjugated goat anti-mouse IgG antibody (1:500, Molecular Probes) for the detection of LAMP-1; anti-Salmonella LPS antiserum (1:1000, Denka Seiken) and Alexa Fluor 647-conjuated goat antirabbit IgG antibody (1:500, Molecular Probes) for the detection of Salmonella; and Texas red-X phalloidin (1:500, Molecular Probes) for the detection of F-actin. The samples were then mounted onto slides using Vectashield solution (Vector Laboratories), and were viewed at $\times 63$ magnification on a confocal laser scanning microscope (LSM510 META, Zeiss). Infected HeLa cells were then scored for the presence of Sifs and association of F-actin. The percentages of each strain that were positive for Sifs and F-actin were recorded for three independent experiments in which a total of 150 infected cells were examined for each strain. Values are given as the means $\pm S D$ of triplicates. Significance was tested by applying Student's $t$ test. Error bars in figures represent SD.

\section{RESULTS}

\section{SlyA interacts directly with the ssrA promoter region}

It has been reported that the dimeric form of SlyA protein interacts with DNA and recognizes short palindromic sequences (Stapleton et al., 2002). In fact, we found that the recognized sequences consist of the palindrome TTATTTATTAAATAA (designated IR in Fig. 1a), located 
(a)

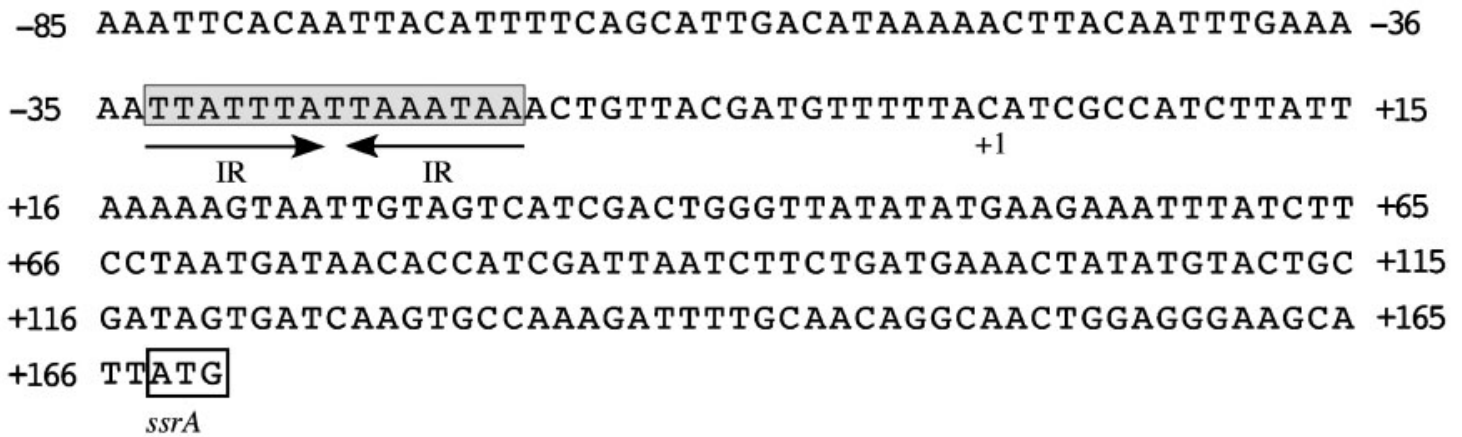

(b)

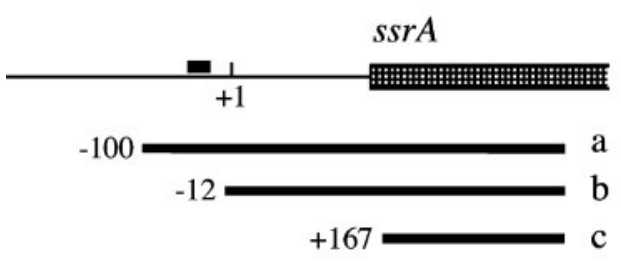

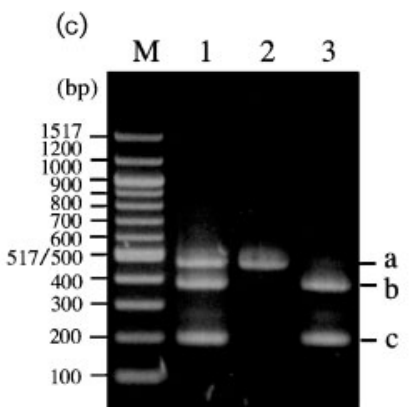

(d)

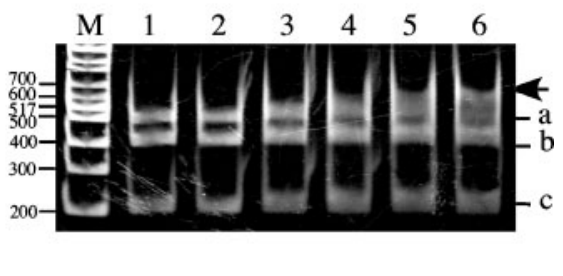

Fig. 1. Interaction of SlyA with the ssrA promoter region. (a) Nucleotide sequence of the ssrA promoter region. The inverted repeat, IR (putative SlyA-binding site), is indicated by arrows. '+1' indicates the transcriptional start site of ssrA (Feng et al., 2003). The numbers indicate the distance in bp from the transcriptional initiation site. The box shows the translational initiation codon of ssrA. (b) DNA fragments with different sizes ( $a, b$ and $c$ ) were used for DNA-binding assays. The numbers on the left denote the position of the fragment end relative to the $s s r A$ transcriptional start site. The upper line shows the $s s r A$ upstream regulatory region and the partial ORF of the $s s r A$ gene, including the transcriptional start site $(+1)$ and the inverted repeat region (black box). (c) Competitive binding assays with Dynabeads-SlyA and DNA fragments a, b and c from the ssrA promoter. Lane 1, input of a DNA mixture (fragments $a, b$ and c); lane 2, DNA bound to Dynabeads-SlyA in a DNA mixture; lane 3, DNA not bound to Dynabeads-SlyA in a DNA mixture. The positions of DNA fragments $a, b$ and $c$ are indicated. (d) Competitive gel-shift assays with purified SlyA and DNA fragments $a, b$ and $c$ from the ssrA promoter. A mixture of DNA fragments was incubated without protein (lane 1) or with increasing amounts of purified SlyA protein $(1.5,3,6,9$ and $12 \mu \mathrm{M}$; lanes 2-6). The positions of DNA fragments $a, b$ and $c$ are indicated. The DNA-SlyA complex is indicated by an arrow. The positions of molecular mass markers are shown on the left.

at positions -33 to -20 on the $s s r A$ promoter region, which is similar to the SlyA-binding sequence TTAGCAAGCTAA described for the slyA promoter (Stapleton et al., 2002). Therefore, we prepared a purified $\mathrm{His}_{6}$-SlyA fusion protein and three different DNA fragments containing segments of the $s s r A$ promoter region (fragment a, $466 \mathrm{bp}$, from -100 to +368 and fragment $\mathrm{b}, 356 \mathrm{bp}$, from -12 to +368 ) and only ssrA ORF (fragment c, $200 \mathrm{bp}$, from +168 to +368 ) (see Fig. 1b) by PCR amplification using the S. enterica serovar Typhimurium SH100 chromosome, and examined the ability of the fragments to bind to the SlyA protein. The Dynabeads-SlyA complex, which immobilized the $\mathrm{His}_{6}$ SlyA fusion protein on Dynabeads via anti-Penta.His antibody (see Methods for details), was used for the DNA-binding assay. Three different DNA fragments ( $a, b$ and c) were incubated with Dynabeads-SlyA, and the bound DNA and the unbound DNA were separated by agarose gel electrophoresis. The binding assays revealed that DNA fragment a was able to bind to Dynabeads-SlyA, whereas fragments $b$ and $c$ were not (Fig. 1c). The same results were obtained when the DNA-binding capacity of purified $\mathrm{His}_{6}$ SlyA fusion protein for the ssrA promoter region was examined by gel mobility shift assays. Mixtures of DNA fragments encompassing different portions of the ssrA promoter region ( $\mathrm{a}, \mathrm{b}$ and $\mathrm{c}$ ) were incubated with increasing concentrations of $\mathrm{His}_{6}$-SlyA fusion protein, and the protein-DNA complex was separated by $4 \%$ PAGE. A single SlyA-DNA complex was found with DNA fragment a, but no complex formation was detected with either fragment $b$ or fragment $c$ (Fig. 1d). These results suggest that SlyA binds to the sequence spanning from nucleotides -100 to -13 of the $s s r A$ promoter.

\section{Construction of a structural model of the SlyA protein}

SlyA consists of a dimer with two functional domains required for DNA binding and dimerization (Stapleton et al., 
2002). To obtain structural and functional information about the SlyA molecule, we constructed a SlyA homodimer model using SKE-CHIMERA (Takeda-Shitaka et al., 2005) and FAMS Ligand\&Complex (Ogata \& Umeyama, 2000; TakedaShitaka et al., 2004a, b, 2005, 2006). The accuracy of comparative models generally depends on sequence identity between the target and the modelled proteins, because errors in alignment or template selection increase for low sequence identities (Baker \& Sali, 2001). Thus, to improve model accuracy, we constructed and examined a number of alignments derived from eight sequence search methods using SKE-CHIMERA. Among the candidate reference proteins for SlyA, the X-ray structures of homodimers of E. faecalis SlyA-like transcriptional factor, SlyA-Ef (PDB ID: 1LJ9), $P$. aeruginosa MexR (PDB ID: 1LNW), B. subtilis YusO protein (PDB ID: 1S3J) and E. coli MarR (PDB ID: 1JGS) were selected, as the sequence identity between SlyA and these four candidates $(23 \%, 20 \%, 19 \%$ and $22 \%$, respectively) was higher than that of other candidate proteins. Although the sequence identities of these four candidates were not high (less than $30 \%$ ), the $E$-values from sequence searches of these proteins were low enough that these proteins could be used as the reference proteins for SlyA. In addition, the secondary structure prediction using PSIPRED (Jones, 1999) indicated that SlyA had a structure similar to that of these proteins. In order to construct the SlyA-DNA complex model, C. diphtheriae DtxR (C102D mutant), of which the $\mathrm{X}$-ray homodimer structure was complexed with DNA (PDB ID: 1F5T), was selected as another candidate reference protein. In 1F5T, $\alpha$-helix $\mathrm{C}$ in each monomer bound in the major groove of the DNA. The structural comparison between 1F5T and the former four candidates (1LJ9, 1LNW, 1S3J and 1JGS) showed that the spacing between the $\alpha$-helix $\mathrm{C}$ of one monomer and the $\alpha$-helix $\mathrm{C}^{\prime}$ of the other monomer in 1F5T was similar to that between the $\alpha$-helix $\alpha 4$ of one monomer and the $\alpha$-helix $\alpha 4^{\prime}$ of the other monomer in 1S3J. Therefore, we superimposed 1F5T onto 1S3J by fitting $\alpha$ helix $C$ and $\alpha$-helix $C^{\prime}$ onto $\alpha$-helix $\alpha 4$ and $\alpha$-helix $\alpha 4^{\prime}$, respectively, and we constructed a model of the complex structure of B. subtilis YusO protein from 1S3J and DNA from 1F5T. The present model of the SlyA-DNA complex was predicted by FAMS Ligand\&Complex based on the alignment shown in Fig. 2(a) using the structure of this YusO and DNA complex as a reference.

\section{Identification of amino acid residues of SlyA that are critical for DNA binding}

As shown in Fig. 2(b), the winged-helix motifs are positioned to interact with a palindromic recognition sequence, with specific contacts expected to occur predominantly between $\alpha$-helix $\alpha 4$ and the wing, and the major groove of the DNA. Therefore, we mutated the slyA gene in plasmid pBAD-slyA at 16 positions in $\alpha 4$ (Pro-61, Ser-62, Leu-63, Val-64, Arg-65, Thr-66, Leu-67, Asp-68, Gln-69, Leu-70, Glu-71 and Asp-72) and in the wing (Arg-85, Arg86, Lys-88 and Arg-89), in order to replace each of these residues with an alanine. Plasmids harbouring the mutated
slyA gene were transformed into the slyA null mutant strain. Considering that mutations that lead to an instability of the SlyA protein could lead to a decrease in its in vivo activity, we tested the production of each mutant SlyA protein by immunoblot analysis using an anti-Penta.His monoclonal antibody. The slyA null mutant strain harbouring an empty plasmid vector $\mathrm{pBAD}$-HisA was used as a negative control. All mutant proteins were expressed at levels comparable to that of the wild-type SlyA under the conditions used in this study (Fig. 3a). To investigate the importance of these residues for DNA binding, the ability of these mutants to promote the expression of ssrA-lacZ reporter gene fusion was examined. Six of the 16 mutant SlyA proteins, i.e. L63A, R65A, L67A, L70A, R86A and K88A, were completely unable to activate ssrA-lacZ expression (Fig. 3b). In addition, the loss of the DNA-binding capacity of these purified mutant SlyA proteins in the $s s r A$ promoter region (fragment a in Fig. 1c) was confirmed by gel mobility shift assays (Fig. 3c). Similarly, these six SlyA mutant proteins were unable to bind to the DNA fragment containing the slyA promoter region (nucleotides -103 to +51 ) (data not shown). These results strongly suggest that six residues in the $\alpha$-helix $\alpha 4$ and wing region are critical for the DNA-binding activity of SlyA. Furthermore, it was of note that the purified mutant SlyA protein V64A showed the ability to bind to all of the DNA fragments tested. In addition, V64A appeared to form higher-molecular-mass DNA complexes (data not shown), thus indicating that a mutation in Val-64 also generates a nonfunctional protein. A sequence alignment of the DNAbinding domain of SlyA revealed that these residues are highly conserved in proteins more closely related to SlyA, including RovA, Hor and Rap, but that they are not conserved in proteins more closely related to MarR (Fig. 4).

\section{Identification of amino acid residues of SlyA that are important for dimerization}

To identify the amino acid residues that are required for the dimerization of SlyA, we searched protein-protein interaction sites as described previously (Terashi et al., 2005), and then individually mutated residues that are thought to be involved in protein-protein interactions within $\alpha$-helices $\alpha 1$ (Leu-9, Leu-12, Leu-15 and Leu-19) and $\alpha 6$ (Ile-114, Ile-118, Leu-126, Leu-129, Ile-130 and Leu-133) to alanine. Plasmids harbouring the mutated $s l y A$ gene were introduced into the Salmonella slyA null mutant strain, and the levels of expression of these point mutants of SlyA were assayed to determine their abundance in vivo by immunoblot analysis using an anti-Penta.His monoclonal antibody. All of the alanine substitutions showed levels of expression similar to that of the wild-type (Fig. 5a). Each SlyA mutant protein was then tested for its ability to activate the $s s r A$ promoter in the Salmonella slyA mutant strain harbouring the ssrA-lacZ fusion gene. Two of 10 mutant SlyA proteins (L12A and L126A) were significantly defective in terms of the activation of $s s r A$ transcription (Fig. 5b). In order to examine the effects of Leu-12 and Leu-126 mutation on the dimerization of SlyA, the L12A and L126A mutant SlyA proteins were 
(b)

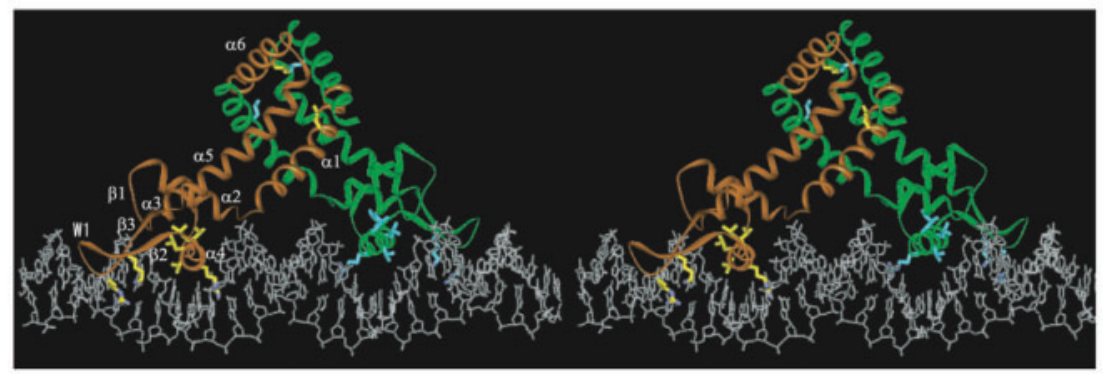

(c)

(d)
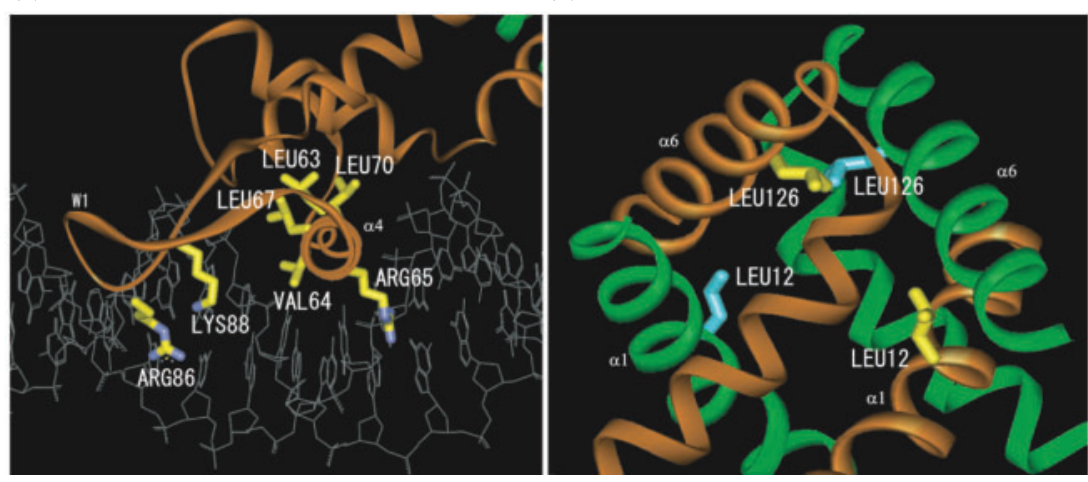

Fig. 2. Homology modelling of the SlyA-DNA complex. (a) Sequence alignment between SlyA and its reference structure of B. subtilis YusO (PDB ID: 1S3J). The numbering of the SlyA primary sequence is indicated above the sequences. The secondary structure elements are indicated under the sequences. $X$ in YusO (1S3J) indicates selenomethionine. The regions of SlyA that were predicted to be $\alpha$-helices and $\beta$-strands by PSIPRED (Jones, 1999) are highlighted in red and blue, respectively. The regions of YusO (1S3J) that were assigned as $\alpha$-helices and $\beta$-strands by STRIDE (Frishman \& Argos, 1995) are highlighted in red and blue, respectively. (b) Stereoview of the homology model of the SlyA-DNA complex. The two molecules of SlyA are shown in orange and green. The secondary structure elements of SlyA are labelled. The DNA molecule is shown as a white stick representation. (c) Close-up view of the interactions between SlyA and DNA. The side-chains of Leu-63, Val-64, Arg-65, Leu-67, Leu-70, Arg-86 and Lys-88 are shown as yellow sticks. (d) Close-up view of the dimerization interface of two molecules. The side-chains of Leu-12 and Leu-126 of two molecules (orange and green molecules) are shown as yellow and cyan sticks, respectively. 
(a)

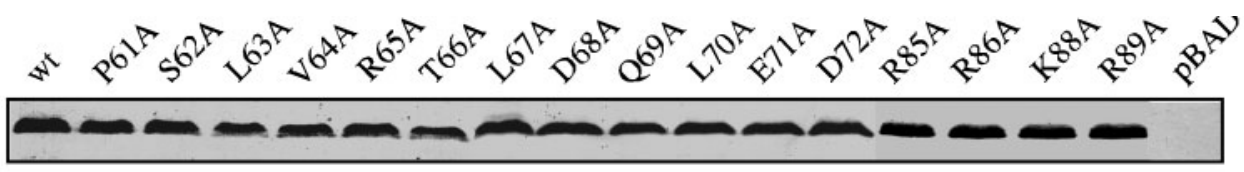

(b)

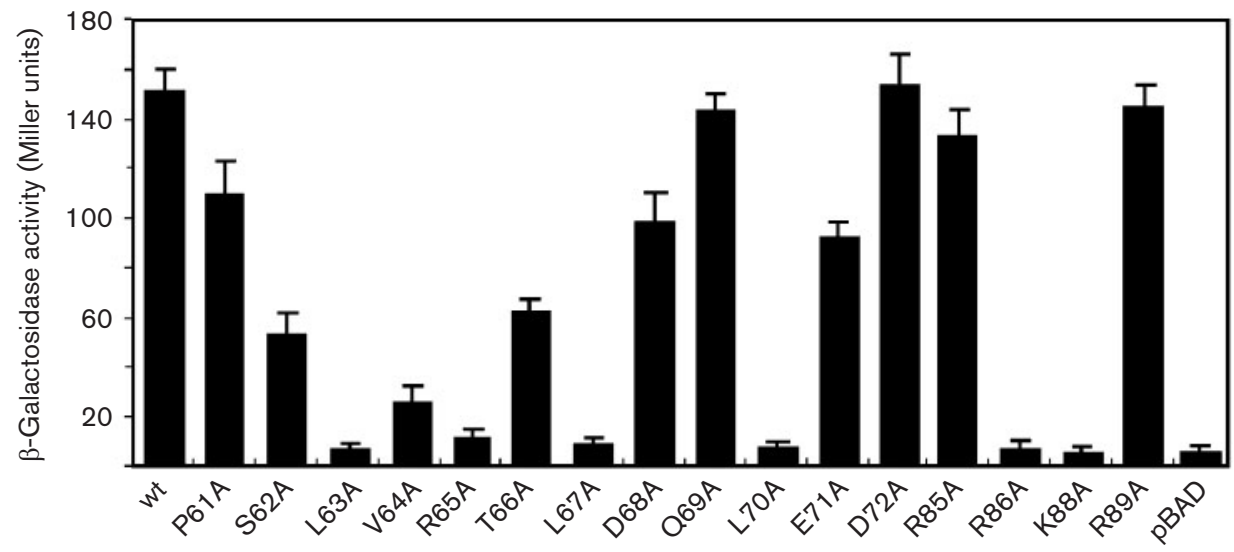

(c)

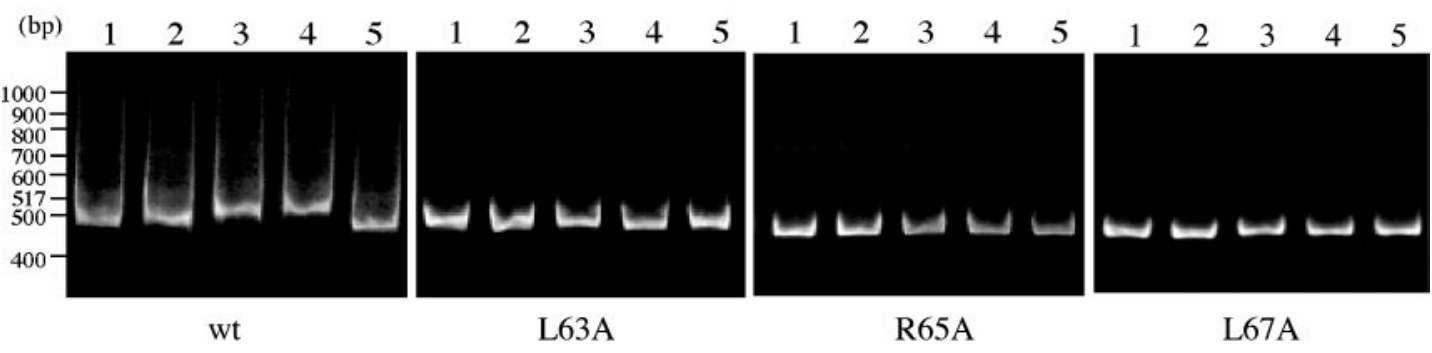

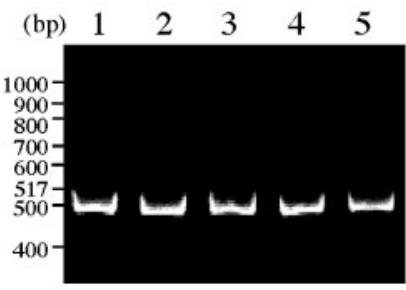

L70A

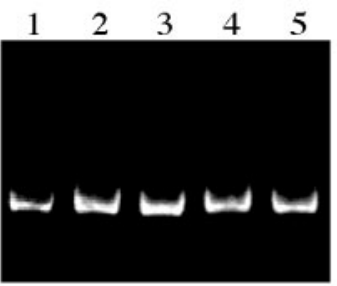

R86A

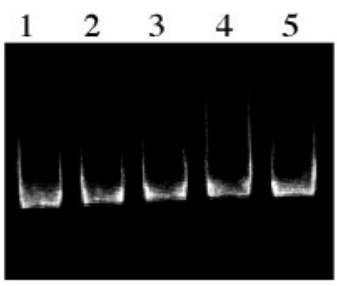

K88A

Fig. 3. DNA-binding properties of substitution mutants of the SlyA protein. (a) Whole-cell lysates corresponding to $1 \times 10^{7}$ bacteria isolated from the $S$. enterica serovar Typhimurium slyA mutant strain harbouring a chromosomal ssrA-lac $Z$ fusion gene (SH122) with plasmids pBAD-slyA and the derivatives of pBAD-slyA were subjected to Western blot analysis with anti-Penta.His antibody. Salmonella strain SH122 harbouring vector pBAD-HisA (pBAD) was used as a negative control. (b) Comparison of the functional activity of the wild-type SlyA and each mutant. The activity of the ssrA promoter was estimated by measuring the $\beta$ galactosidase activity. (c) Binding of purified wild-type SlyA (wt) and point-mutant SlyA proteins (L63A, R65A, L67A, L70A, R86A and K88A) to DNA fragment a containing the putative SlyA-binding site of the ssrA regulatory region (see Fig. 1c). The DNA fragment was incubated without protein (lane 1), with increasing amounts of the purified SlyA protein (6, 9 and $12 \mu \mathrm{M}$; lanes 2-4), or with $1.5 \mathrm{mM}$ BSA (lane 5). The corresponding molecular masses are indicated on the left.

purified and subjected to cross-linking experiments with DSS. As assessed by SDS-PAGE, the apparent molecular size of DSS cross-linked wild-type $\mathrm{His}_{6}$-SlyA $(20.7 \mathrm{kDa}$, with a 40 aa N-terminal $\mathrm{His}_{6}$ tag) is $42 \mathrm{kDa}$, which is approximately the expected size of $41.4 \mathrm{kDa}$ for dimeric $\mathrm{His}_{6}-\mathrm{SlyA}$
(Fig. 5c). However, mutant SlyA protein L12A failed to form a detectable cross-linked dimer (Fig. 5c). While the L126A substitution mutation significantly affected the levels of expression of ssrA in Salmonella, the mutant protein showed reduced but detectable dimer formation upon DSS 


\begin{tabular}{|c|c|c|}
\hline SlyA & 61 PSLVRTLDQLED & 85 RRAKR \\
\hline RovA & 61 PSLVRTLDQLEE & 85 RRAKR \\
\hline Hor & 61 PSLVRTLDQLEE & 85 RRAKR \\
\hline Rap & 61 PSLVRTLDQLED & 85 RRAKR \\
\hline MarR & 69 GALTRMLDRLVC & 93 KRGVL \\
\hline SlyA-Ef & 59 TTAARAIKRLEE & 83 KKIKR \\
\hline CinR & 61 STMTVQLARLEK & 86 KKAYR \\
\hline PecS & 86 STLTSRLDRLEQ & ..110 RRSVN \\
\hline MexR & 66 ALITRKIRELEG & .. 90 QRSFQ \\
\hline rA & 86 TNATRIADELEK & $\ldots 110$ RRCL \\
\hline
\end{tabular}

Fig. 4. Sequence alignment of amino acid residues of the winged-helix region of the MarR/SlyA family. The numbers indicate the position of the amino acid residues. The proteins used for the alignment were from Salmonella enterica serovar Typhimurium (SlyA), Yersinia enterocolitica (RovA), Erwinia carotovora (Hor), Serratia marcescens (Rap), Escherichia coli (MarR), Enterococcus faecalis (SlyA-Ef), Butyrivibrio fibrisolvens (CinR), Erwinia chrysanthemi (PecS), Pseudomonas aeruginosa (MexR) and E. coli (MprA).

cross-linking followed by SDS-PAGE (Fig. 5c). In contrast, eight SlyA mutant proteins that were able to promote $s s \mathrm{~A}$ transcription were observed in the dimer form of each purified protein (data not shown). Furthermore, these two mutant SlyA proteins, L12A and L126A, abolished binding to the $s s r A$ promoter (data not shown). These results suggest that at least amino acid residue Leu-12 (within $\alpha$-helix $\alpha 1$ ) is required for SlyA to form a dimer and Leu-126 (within $\alpha$ helix $\alpha 6$ ) for efficient dimerization.

\section{SlyA mutant derivatives fail to restore the ability of a slyA mutant strain to induce Sifs and $F$-actin meshwork formation in vivo}

In line with the reduction in SPI-2 expression by mutation of $s l y A$, a slyA mutant strain in infected cells was unable to induce Sifs and intracellular F-actin meshwork formation (Linehan et al., 2005), phenotypes which are dependent on SPI-2 TTSS, and both phenotypes are required for intracellular survival and replication by Salmonella (Waterman \& Holden, 2003). To examine whether mutant SlyA proteins would be able to restore the induction of Sif formation and actin reorganization during intracellular replication, HeLa cells infected with Salmonella strains carrying plasmids expressing the wild-type and mutant SlyA proteins were fixed and subsequently labelled with an antiLAMP-1 antibody to reveal Sifs and with Texas redphalloidin to detect F-actin. In these experiments, the $s s r A$ mutant was used as a negative control. In addition, to confirm that Sif formation and actin reorganization are dependent on SPI-2 TTSS function, we used the SPI-2 ssaV null mutant, which lacks an essential structure component of SPI-2 TTSS. At $20 \mathrm{~h}$ after bacterial invasion, approximately $65 \%$ of the cells infected with wild-type bacteria contained Sifs, whereas Sifs were detected in less than $1 \%$ of the cells infected with SPI-2 mutant strains carrying mutations in either ssrA or ssaV. Less than $1 \%$ of the cells infected with the slyA mutant strain contained Sifs (Fig. 6a). In addition, confocal microscopy showed a strong
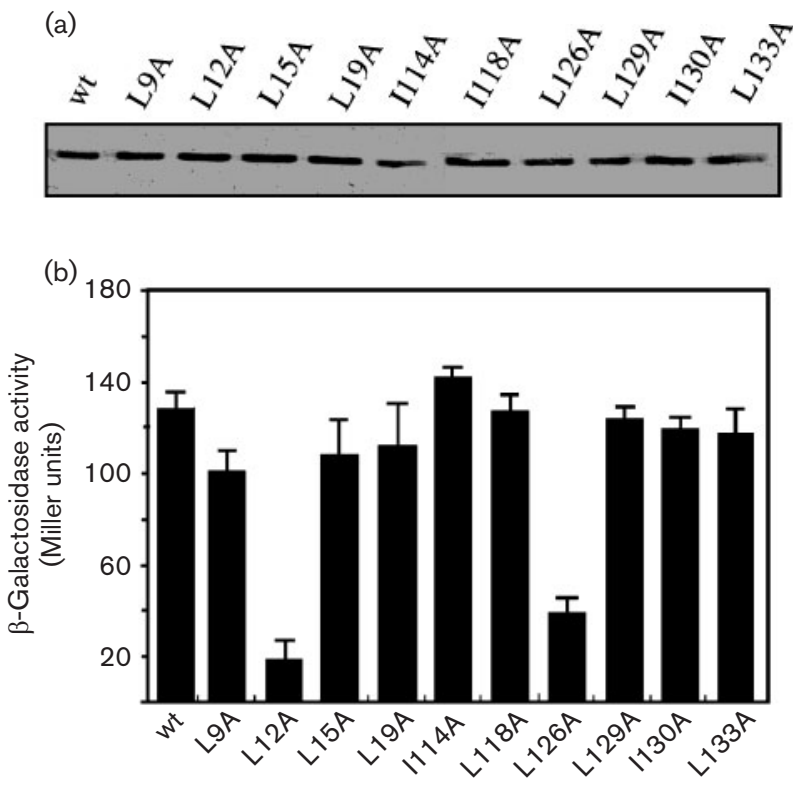

(c)

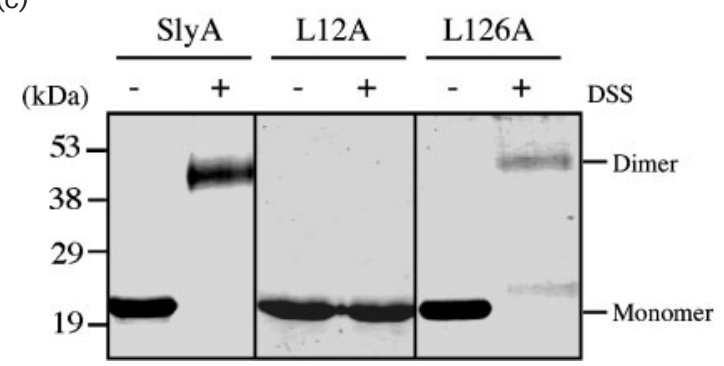

Fig. 5. Dimerization properties of the substitution mutants of the SlyA protein. (a) Whole-cell lysates corresponding to $1 \times 10^{7}$ bacteria isolated from the $S$. enterica serovar Typhimurium slyA mutant strain harbouring chromosome ssrAlac $Z$ fusion gene (SH122) with $\mathrm{pBAD}$-slyA and the derivatives of pBAD-slyA were subjected to Western blot analysis with anti-Penta.His antibody. (b) Comparison of the functional activity of the wild-type SlyA and that of each mutant. (c) Crosslinking of SlyA and its mutant derivatives (L12A and L126A) with DSS. The positions of molecular mass markers are shown on the left.

co-localization of F-action and LAMP-1 around the wildtype bacteria (approx. $80 \%$ of the bacteria), but cells infected with the $s s a V$ mutant strain did not show such colocalization $(\sim 10 \%$ of the bacteria). In contrast to the lack of an association in the case of the $s s a V$ mutant strain, a close association between F-actin and LAMP-1 was observed in $\sim 50 \%$ of the $s s r A$ mutant bacteria. This leaky phenotype was probably due to low levels of expression of SsrB, as was also seen in the ssrA null mutant strain (Feng et al., 2003, 2004). A similar pattern of co-localization was observed in the case of the slyA mutant strain (Fig. 6b), thus confirming the results of previous studies (Linehan et al., 2005). Expression of the wild-type SlyA from a plasmid restored the ability of the mutant strain to induce Sif formation and 

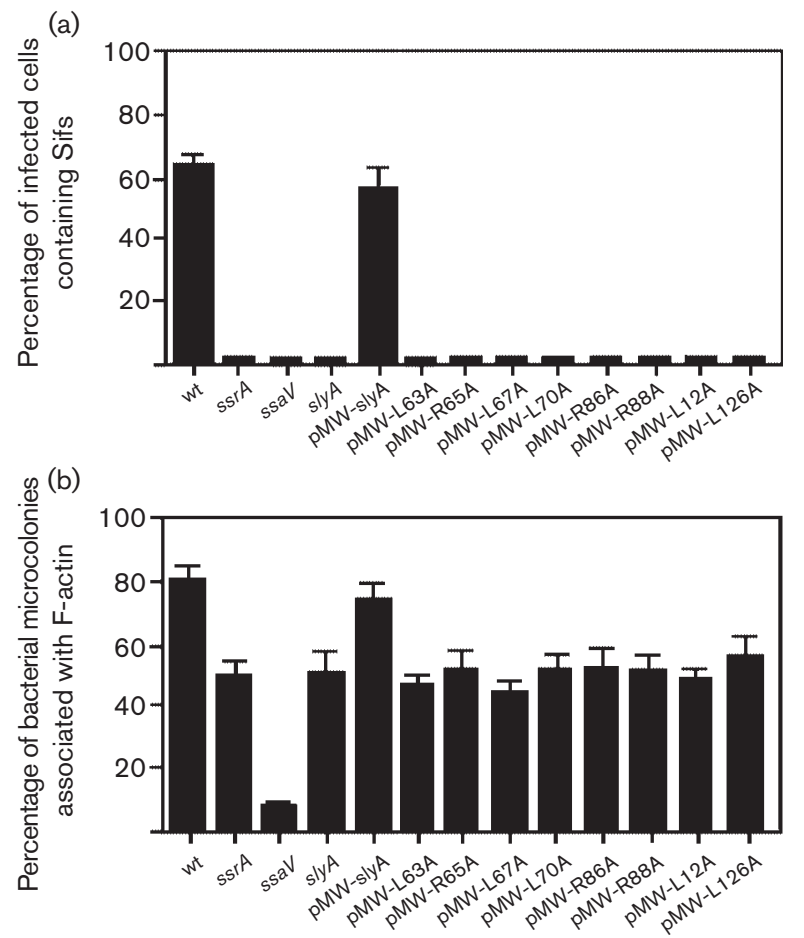

Fig. 6. Complementation analysis of $S$. enterica serovar Typhimurium slyA mutant strain $(\mathrm{SH} 110)$ by introduction of plasmids expressing wild-type and point-mutant SlyA. (a) The percentage of infected cells showing Sif formation was determined at $20 \mathrm{~h}$ after bacterial invasion, as described previously (Beuzon et al., 2001). (b) The percentage of infected cells in which the bacteria were surrounded by F-actin was determined at $20 \mathrm{~h}$ after bacterial invasion, as described previously ( $\mathrm{Yu}$ et al., 2002).

F-actin reorganization in infected cells, but mutant SlyA derivatives were not associated with such restored ability (Fig. 6b). Thus, the amino acids that are important for SlyA function in vitro are also essential for the efficient expression of SPI-2 function via the activation of the ssrA gene in vivo.

\section{DISCUSSION}

The regulatory protein SlyA plays major roles in Salmonella virulence, resistance to oxidative stress and resistance to antimicrobial peptides (Buchmeier et al., 1997; Daniels et al., 1996; Kaneko et al., 2002; Libby et al., 1994; Shi et al., 2004; Watson et al., 1999). Recently, it was reported that an ssrAlacZ fusion gene in E. coli is activated in the presence of SlyA (Feng et al., 2004). In addition, using cDNA microarray analysis, a number of genes in the SlyA regulon have been identified, including the $s s r A B$ locus, which regulates the expression of genes encoded by SPI-2 (Navarre et al., 2005). Consistent with these data, it has been demonstrated that the inability of a Salmonella slyA mutant strain to proliferate in phagocytes and host tissues is due to the loss of SPI-2 function (Linehan et al., 2005). In this study, to analyse the molecular mechanism of SlyA in Salmonella virulence, we characterized SlyA function in the context of the $s s r A$ regulatory process. We demonstrated that SlyA acts directly on the ssrA promoter and that the mutation in SlyA that disables DNA-binding activity resulted in the reduced expression of $s s r A$, in turn leading to a loss of SPI-2 function.

We have shown that SlyA controls ssrA transcription directly by binding to the $s s r A$ promoter. Competitive DNA-binding assays with purified $\mathrm{His}_{6}$-SlyA protein revealed that SlyA interacts with nucleotides within the region -100 to -13 of the $s s r A$ promoter, which is essential for the formation of the SlyA-DNA complex. In this region, we found a $7 \mathrm{bp}$ inverted repeat sequence, TTATTTATTAAATAA (positions -33 to -19 of the $s s r A$ promoter region), which serves as the putative SlyA binding site, and which resembles the putative consensus SlyA-binding motif (TTAGCAAGCTAA) described for the slyA promoter in vitro (Stapleton et al., 2002). Interestingly, although additional experiments including DNA footprinting assays will be required to provide further evidence of the sequence-specific binding of SlyA, the location of the SlyA-binding site appears to be a region within the -35 and -10 promoter sequence, which is an unusual site for a transcriptional activating protein. However, SlyA has also been shown to have binding sites downstream of the transcriptional start site in the pagC and $u g t L$ promoters that are required for gene transcription (Navarre et al., 2005; Shi et al., 2004).

Members of the MarR/SlyA family both activate and repress the expression of several genes. The data presented for SlyA and its homologue, RovA from Yersinia, suggest that the regulatory proteins of this family may positively regulate genes by acting as derepressors (Heroven et al., 2004; Wyborn et al., 2004). For example, E. coli hlyE (also known as $c l y A$ and $s h e A$ ), which encodes a novel pore-forming toxin, is regulated positively by the global transcriptional factors FNR (fumarate and nitrate reduction) and CRP (cAMP receptor protein) and by SlyA, and negatively by the nucleoid-structuring protein H-NS (Wyborn et al., 2004). Both H-NS and SlyA interact directly with the hlyE promoter region and occupy the same sequence that overlaps the binding site for the global transcriptional factors, suggesting that SlyA functions as a derepressor that competes with $\mathrm{H}-\mathrm{NS}$ for the binding site within the $h l y E$ promoter. Similarly, in the case of $s s r A$, the binding of SlyA might change the local nucleoprotein structure of the chromosome by competing with the negative action of repressors (such as H-NS), and enabling activation of $s s r A$ by response regulators $\mathrm{OmpR}$ and $\mathrm{SsrB}$.

SlyA of S. enterica has been identified as a member of the MarR/SlyA family, based on the similarity of its amino acid sequence to that of other members of this family (Ludwig et al., 1995; Thomson et al., 1997). Although the amino acid sequence similarity of this SlyA is relatively low, we demonstrated that the structure of this SlyA is very similar to the structures of the other MarR family proteins. The crystal structures of this protein family (which includes 
MarR, MexR, SarR, SlyA-Ef, AphA and OhrR) revealed that the protein forms a homodimer, with each subunit possessing a winged-helix DNA binding motif, which is required for DNA binding (Alekshun et al., 2001; De Silva et al., 2005; Hong et al., 2005; Lim et al., 2002; Liu et al., 2001; Wu et al., 2003). Furthermore, winged-helix proteins characteristically bind to DNA sequences containing a palindromic or pseudopalindromic structure. For example, the binding site of MarR contains two inverted $5 \mathrm{bp}$ sequences separated by 2 bp (Egland \& Harwood, 1999); moreover, in the case of MexR, the $5 \mathrm{bp}$ inverted repeat sequences are separated by 5 bp (Evans et al., 2001). The binding site for SlyA contains a $5 \mathrm{bp}$ inverted repeat separated by $2 \mathrm{bp}$ at the $s l y A$ promoter, although there is variation within DNA sequences among the different promoters.

The structure of OhrR bound to the ohrA operator complex reveals the DNA-binding mechanism for a regulator in the MarR family (Hong et al., 2005). When OhrR binds to DNA, the $\alpha 4$ helix of the helix-turn-helix domain makes contact with the major groove, and the wing, composed of strands $\beta 2$ and $\beta 3$ and their connecting loop, interacts with the minor groove. In addition to the winged helix-turn-helix motif, the helix-helix DNA-binding element interacts with the phosphate backbone of the DNA (Hong et al., 2005). Thus, OhrR dimer locates the target DNA by an extended wing, a helix-turn-helix motif and the helix-helix interaction motif. In our model of the SlyA structure in complex with DNA, the wing is packed alongside the DNA, spanning the phosphate backbones of both strands on either side of the minor groove, and helix $\alpha 4$ is thus expected to be involved in interactions with the major groove. Since the similarity among MarR/SlyA family proteins appears to be limited to the DNA-binding domains, the requirement of a helix-helix motif for DNA binding is unclear. Further structural studies of SlyA in the presence of DNA will be required to fully understand the nature of the interaction between SlyA and a target DNA.

The reported structures of MarR family proteins show that the dimerization domain includes $\alpha$-helices in the $\mathrm{N}$ terminal and C-terminal regions of each monomer (Alekshun et al., 2001; De Silva et al., 2005; Hong et al., 2005; Lim et al., 2002; Liu et al., 2001; Wu et al., 2003). The protein-protein interaction is primarily mediated by a number of hydrophobic interactions, and is further stabilized by hydrogen bonds and salt-bridge pairs. Likewise, in the predicted SlyA dimer structure, the dimer interface appears to be present between an $\mathrm{N}$-terminal $\alpha$ helix, $\alpha 1$, and a C-terminal $\alpha$-helix, $\alpha 6$. In line with this model, the L12A mutation located in $\alpha$-helix $\alpha 1$ and the L126A mutation located in $\alpha$-helix $\alpha 6$ were shown to reduce the ability of the protein to dimerize. Whereas the effects of L126A mutation on dimerization were quite weak, these mutations exerted significant effects on both the expression of $s s r A$ and SPI-2 function in infected HeLa cells. In addition, the mutant SlyA protein, which cannot form a dimer, is incapable of binding to DNA. Thus, the amino acid residues that are critical for the formation and/or maintenance of the dimer structure are also important for SlyA function as a transcriptional regulator.

More recently, the structure-function analysis has been reported of Yersinia RovA, which is required for full virulence and efficient colonization by Yersinia (Revell \& Miller, 2000; Tran et al., 2005). Functionally important domains of RovA were determined by random mutagenesis and terminal deletions. Consistent with our study, Tran et al. (2005) identified several substitutions in the winged-helix domain in the centre of the molecule, which is essential for DNA binding, and isolated amino acid changes within both termini that reduced dimer formation. In addition, they proposed a structure model for the RovA protein, which is very similar to that of SlyA in this study. However, several functional amino acids of RovA required for efficient DNA binding were different from those of SlyA. This difference might be due to diverse DNA targets of the two proteins, showing that regulatory proteins belonging to the SlyA family are highly adapted for species-specific regulation.

\section{ACKNOWLEDGEMENTS}

We would like to thank Keiko Oshima, Yuichi Okajima and Masato Hosono for their technical assistance. In addition, we are grateful to Mitsuo Iwadate and Daisuke Takaya for helpful discussions.

This work was supported in part by Grants-in-Aid for Scientific Research (C) (17590398) and for Young Scientists (B) (17790291 and 17790292), and by a 21st Century COE Research Grant from the Japanese Ministry of Education, Culture, Sports, Sciences and Technology.

\section{REFERENCES}

Alekshun, M. N. \& Levy, S. B. (1997). Regulation of chromosomally mediated multiple antibiotic resistance: the mar regulon. Antimicrob Agents Chemother 41, 2067-2075.

Alekshun, M. N., Levy, S. B., Mealy, T. R., Seaton, B. A. \& Head, J. F. (2001). The crystal structure of MarR, a regulator of multiple antibiotic resistance, at $2.3 \AA$ resolution. Nat Struct Biol 8, 710-714.

Altschul, S. F., Madden, T. L., Schaffer, A. A., Zhang, J., Zhang, Z., Miller, W. \& Lipman, D. J. (1997). Gapped BLAST and PSI-BLAST: a new generation of protein database search programs. Nucleic Acids Res 25, 3389-3402.

Baker, D. \& Sali, A. (2001). Protein structure prediction and structural genomics. Science 294, 93-96.

Berman, H. M., Westbrook, J., Feng, Z., Gilliland, G., Bhat, T. N., Weissig, H., Shindyalov, I. N. \& Bourne, P. E. (2000). The Protein Data Bank. Nucleic Acids Res 28, 235-242.

Beuzon, C. R., Unsworth, K. E. \& Holden, D. W. (2001). In vivo genetic analysis indicates that PhoP-PhoQ and the Salmonella pathogenicity island 2 type III secretion system contribute independently to Salmonella enterica serovar Typhimurium virulence. Infect Immun 69, 7254-7261.

Bijlsma, J. J. \& Groisman, E. A. (2005). The PhoP/PhoQ system controls the intramacrophage type three secretion system of Salmonella enterica. Mol Microbiol 57, 85-96. 
Brumell, J. H., Goosney, D. L. \& Finlay, B. B. (2002). SifA, a type III secreted effector of Salmonella typhimurium, directs Salmonella-induced filament (Sif) formation along microtubules. Traffic 3, 407-415.

Buchmeier, N., Bossie, S., Chen, C. Y., Fang, F. C., Guiney, D. G. \& Libby, S. J. (1997). SlyA, a transcriptional regulator of Salmonella typhimurium, is required for resistance to oxidative stress and is expressed in the intracellular environment of macrophages. Infect Immun 65, 3725-3730.

Cirillo, D. M., Valdivia, R. H., Monack, D. M. \& Falkow, S. (1998). Macrophage-dependent induction of the Salmonella pathogenicity island 2 type III secretion system and its role in intracellular survival. Mol Microbiol 30, 175-188.

Daniels, J. J., Autenrieth, I. B., Ludwig, A. \& Goebel, W. (1996). The gene slyA of Salmonella typhimurium is required for destruction of $\mathrm{M}$ cells and intracellular survival but not for invasion or colonization of the murine small intestine. Infect Immun 64, 5075-5084.

Deiwick, J., Nikolaus, T., Erdogan, S. \& Hensel, M. (1999). Environmental regulation of Salmonella pathogenicity island 2 gene expression. Mol Microbiol 31, 1759-1773.

De Silva, R. S., Kovacikova, G., Lin, W., Taylor, R. K., Skorupski, K. \& Kull, F. J. (2005). Crystal structure of the virulence gene activator AphA from Vibrio cholerae reveals it is a novel member of the winged helix transcription factor superfamily. J Biol Chem 280, 13779-13783.

Egland, P. G. \& Harwood, C. S. (1999). BadR, a new MarR family member, regulates anaerobic benzoate degradation by Rhodopseudomonas palustris in concert with AadR, an Fnr family member. J Bacteriol 181, 2102-2109.

Evans, K., Adewoye, L. \& Poole, K. (2001). MexR repressor of the mexAB-oprM multidrug efflux operon of Pseudomonas aeruginosa: identification of MexR binding sites in the mexA-mexR intergenic region. J Bacteriol 183, 807-812.

Feng, X., Oropeza, R. \& Kenney, L. J. (2003). Dual regulation by phospho-OmpR of $s s r A / B$ gene expression in Salmonella pathogenicity island 2. Mol Microbiol 48, 1131-1143.

Feng, X., Walthers, D., Oropeza, R. \& Kenney, L. J. (2004). The response regulator SsrB activates transcription and binds to a region overlapping OmpR binding sites at Salmonella pathogenicity island 2. Mol Microbiol 54, 823-835.

Frishman, D. \& Argos, P. (1995). Knowledge-based protein secondary structure assignment. Proteins 23, 566-579.

Gallois, A., Klein, J. R., Allen, L. A., Jones, B. D. \& Nauseef, W. M. (2001). Salmonella pathogenicity island 2-encoded type III secretion system mediates exclusion of NADPH oxidase assembly from the phagosomal membrane. J Immunol 166, 5741-5748.

Garmendia, J., Beuzon, C. R., Ruiz-Albert, J. \& Holden, D. W. (2003). The roles of SsrA-SsrB and OmpR-EnvZ in the regulation of genes encoding the Salmonella typhimurium SPI-2 type III secretion system. Microbiology 149, 2385-2396.

Gotoh, H., Okada, N., Kim, Y. G., Shiraishi, K., Hirami, N., Haneda, T., Kurita, A., Kikuchi, Y. \& Danbara, H. (2003). Extracellular secretion of the virulence plasmid-encoded ADP-ribosyltransferase SpvB in Salmonella. Microb Pathog 34, 227-238.

Guignot, J., Caron, E., Beuzon, C., Bucci, C., Kagan, J., Roy, C. \& Holden, D. W. (2004). Microtubule motors control membrane dynamics of Salmonella-containing vacuoles. J Cell Sci 117, 1033-1045.

Hensel, M. (2000). Salmonella pathogenicity island 2. Mol Microbiol 36, 1015-1023.

Hensel, M., Shea, J. E., Waterman, S. R., Mundy, R., Nikolaus, T., Banks, G., Vazquez-Torres, A., Gleeson, C., Fang, F. C. \& Holden, D. W. (1998). Genes encoding putative effector proteins of the type
III secretion system of Salmonella pathogenicity island 2 are required for bacterial virulence and proliferation in macrophages. Mol Microbiol 30, 163-174.

Heroven, A. K., Nagel, G., Tran, H. J., Parr, S. \& Dersch, P. (2004). RovA is autoregulated and antagonizes H-NS-mediated silencing of invasin and rovA expression in Yersinia pseudotuberculosis. Mol Microbiol 53, 871-888.

Hong, M., Fuangthong, M., Helmann, J. D. \& Brennan, R. G. (2005). Structure of an OhrR-ohrA operator complex reveals the DNA binding mechanism of the MarR family. Mol Cell 20, 131-141.

Jones, D. T. (1999). Protein secondary structure prediction based on position-specific scoring matrices. J Mol Biol 292, 195-202.

Kaneko, A., Mita, M., Sekiya, K., Matsui, H., Kawahara, K. \& Danbara, H. (2002). Association of a regulatory gene, slyA with a mouse virulence of Salmonella serovar Choleraesuis. Microbiol Immunol 46, 109-113.

Kawakami, T., Kaneko, A., Okada, N., Imajoh-Ohmi, S., Nonaka, T., Matsui, H., Kawahara, K. \& Danbara, H. (1999). TTG as the initiation codon of Salmonella slyA, a gene required for survival within macrophages. Microbiol Immunol 43, 351-357.

Laskowski, R. A., MacArthur, M. W., Moss, D. S. \& Thornton, J. M. (1993). PROCHECK: a program to check the stereochemical quality of protein structures. J Appl Cryst 26, 283-291.

Lee, A. K., Detweiler, C. S. \& Falkow, S. (2000). OmpR regulates the two-component system SsrA-SsrB in Salmonella pathogenicity island 2. J Bacteriol 182, 771-781.

Libby, S. J., Goebel, W., Ludwig, A., Buchmeier, N., Bowe, F., Fang, F. C., Guiney, D. G., Songer, J. G. \& Heffron, F. (1994). A cytolysin encoded by Salmonella is required for survival within macrophages. Proc Natl Acad Sci U S A 91, 489-493.

Lim, D., Poole, K. \& Strynadka, N. C. (2002). Crystal structure of the MexR repressor of the mexRAB-oprM multidrug efflux operon of Pseudomonas aeruginosa. J Biol Chem 277, 29253-29259.

Linehan, S. A., Rytkonen, A., Yu, X. J., Liu, M. \& Holden, D. W. (2005). SlyA regulates function of Salmonella pathogenicity island 2 (SPI-2) and expression of SPI-2-associated genes. Infect Immun 73, 4354-4362.

Liu, Y., Manna, A., Li, R., Martin, W. E., Murphy, R. C., Cheung, A. L. \& Zhang, G. (2001). Crystal structure of the SarR protein from Staphylococcus aureus. Proc Natl Acad Sci U S A 98, 6877-6882.

Ludwig, A., Tengel, C., Bauer, S., Bubert, A., Benz, R., Mollenkopf, H. J. \& Goebel, W. (1995). SlyA, a regulatory protein from Salmonella typhimurium, induces a haemolytic and pore-forming protein in Escherichia coli. Mol Gen Genet 249, 474-486.

Menard, R., Sansonetti, P. J. \& Parsot, C. (1993). Nonpolar mutagenesis of the ipa genes defines IpaB, IpaC, and IpaD as effectors of Shigella flexneri entry into epithelial cells. J Bacteriol 175, 5899-5906.

Meresse, S., Unsworth, K. E., Habermann, A., Griffiths, G., Fang, F., Martinez-Lorenzo, M. J., Waterman, S. R., Gorvel, J. P. \& Holden, D. W. (2001). Remodelling of the actin cytoskeleton is essential for replication of intravacuolar Salmonella. Cell Microbiol 3, 567-577.

Miao, E. A., Freeman, J. A. \& Miller, S. I. (2002). Transcription of the SsrAB regulon is repressed by alkaline $\mathrm{pH}$ and is independent of PhoPQ and magnesium concentration. J Bacteriol 184, 1493-1497.

Miki, T., Okada, N. \& Danbara, H. (2004). Two periplasmic disulfide oxidoreductases, DsbA and SrgA, target outer membrane protein SpiA, a component of the Salmonella pathogenicity island 2 type III secretion system. J Biol Chem 279, 34631-34642.

Miller, J. H. (1992). A Short Course in Bacterial Genetics. Cold Spring Harbor, NY: Cold Spring Harbor Laboratory. 
Navarre, W. W., Halsey, T. A., Walthers, D., Frye, J., McClelland, M., Potter, J. L., Kenney, L. J., Gunn, J. S., Fang, F. C. \& other authors (2005). Co-regulation of Salmonella enterica genes required for virulence and resistance to antimicrobial peptides by SlyA and PhoP/ PhoQ. Mol Microbiol 56, 492-508.

Norte, V. A., Stapleton, M. R. \& Green, J. (2003). PhoP-responsive expression of the Salmonella enterica serovar Typhimurium slyA gene. J Bacteriol 185, 3508-3514.

Ochman, H., Soncini, F. C., Solomon, F. \& Groisman, E. A. (1996). Identification of a pathogenicity island required for Salmonella survival in host cells. Proc Natl Acad Sci U S A 93, 7800-7804.

Ogata, K. \& Umeyama, H. (2000). An automatic homology modeling method consisting of database searches and simulated annealing. J Mol Graph Model 18, 258-272, 305-256.

Revell, P. A. \& Miller, V. L. (2000). A chromosomally encoded regulator is required for expression of the Yersinia enterocolitica inv gene and for virulence. Mol Microbiol 35, 677-685.

Shea, J. E., Hensel, M., Gleeson, C. \& Holden, D. W. (1996). Identification of a virulence locus encoding a second type III secretion system in Salmonella typhimurium. Proc Natl Acad Sci U S A 93, 2593-2597.

Shi, Y., Latifi, T., Cromie, M. J. \& Groisman, E. A. (2004). Transcriptional control of the antimicrobial peptide resistance $u g t L$ gene by the Salmonella PhoP and SlyA regulatory proteins. J Biol Chem 279, 38618-38625.

Simon, R., Priefer, U. \& Puhler, A. (1983). A broad host range mobilization system for in vivo genetic engineering: transposon mutagenesis in Gram-negative bacteria. Bio/Technology 1, 784-791.

Spory, A., Bosserhoff, A., von Rhein, C., Goebel, W. \& Ludwig, A. (2002). Differential regulation of multiple proteins of Escherichia coli and Salmonella enterica serovar Typhimurium by the transcriptional regulator SlyA. J Bacteriol 184, 3549-3559.

Stapleton, M. R., Norte, V. A., Read, R. C. \& Green, J. (2002). Interaction of the Salmonella typhimurium transcription and virulence factor SlyA with target DNA and identification of members of the SlyA regulon. J Biol Chem 277, 17630-17637.

Steele-Mortimer, O., Brumell, J. H., Knodler, L. A., Meresse, S., Lopez, A. \& Finlay, B. B. (2002). The invasion-associated type III secretion system of Salmonella enterica serovar Typhimurium is necessary for intracellular proliferation and vacuole biogenesis in epithelial cells. Cell Microbiol 4, 43-54.

Takeda-Shitaka, M., Nojima, H., Takaya, D., Kanou, K., Iwadate, M. \& Umeyama, H. (2004a). Evaluation of homology modeling of the severe acute respiratory syndrome (SARS) coronavirus main protease for structure based drug design. Chem Pharm Bull 52, 643-645.

Takeda-Shitaka, M., Takaya, D., Chiba, C., Tanaka, H. \& Umeyama, H. (2004b). Protein structure prediction in structure based drug design. Curr Med Chem 11, 551-558.

Takeda-Shitaka, M., Terashi, G., Takaya, D., Kanou, K., Iwadate, M. \& Umeyama, H. (2005). Protein structure prediction in CASP6 using CHIMERA and FAMS. Proteins 61, 122-127.
Takeda-Shitaka, M., Terashi, G., Chiba, C., Takaya, D. \& Umeyama, H. (2006). FAMS complex: a fully automated homology modeling system for protein complex structures. Med Chem 2, 191-201.

Terashi, G., Takeda-Shitaka, M., Takaya, D., Komatsu, K. \& Umeyama, H. (2005). Searching for protein-protein interaction sites and docking by the methods of molecular dynamics, grid scoring, and the pairwise interaction potential of amino acid residues. Proteins 60, 289-295.

Thomson, N. R., Cox, A., Bycroft, B. W., Stewart, G. S., Williams, P. \& Salmond, G. P. (1997). The Rap and Hor proteins of Erwinia, Serratia and Yersinia: a novel subgroup in a growing superfamily of proteins regulating diverse physiological processes in bacterial pathogens. Mol Microbiol 26, 531-544.

Tobe, T., Schoolnik, G. K., Sohel, I., Bustamante, V. H. \& Puente, J. L. (1996). Cloning and characterization of $b f p T V W$, genes required for the transcriptional activation of $b f p A$ in enteropathogenic Escherichia coli. Mol Microbiol 21, 963-975.

Tran, H. J., Heroven, A. K., Winkler, L., Spreter, T., Beatrix, B. \& Dersch, P. (2005). Analysis of RovA, a transcriptional regulator of Yersinia pseudotuberculosis virulence that acts through antirepression and direct transcriptional activation. J Biol Chem 280, 42423-42432.

Valdivia, R. H. \& Falkow, S. (1997). Fluorescence-based isolation of bacterial genes expressed within host cells. Science 277, 2007-2011.

Vazquez-Torres, A., Xu, Y., Jones-Carson, J., Holden, D. W., Lucia, S. M., Dinauer, M. C., Mastroeni, P. \& Fang, F. C. (2000). Salmonella pathogenicity island 2-dependent evasion of the phagocyte NADPH oxidase. Science 287, 1655-1658.

Waterman, S. R. \& Holden, D. W. (2003). Functions and effectors of the Salmonella pathogenicity island 2 type III secretion system. Cell Microbiol 5, 501-511.

Watson, P. R., Paulin, S. M., Bland, A. P., Libby, S. J., Jones, P. W. \& Wallis, T. S. (1999). Differential regulation of enteric and systemic salmonellosis by slyA. Infect Immun 67, 4950-4954.

Worley, M. J., Ching, K. H. \& Heffron, F. (2000). Salmonella SsrB activates a global regulon of horizontally acquired genes. $\mathrm{Mol}$ Microbiol 36, 749-761.

Wu, R. Y., Zhang, R. G., Zagnitko, O., Dementieva, I., Maltzev, N., Watson, J. D., Laskowski, R., Gornicki, P. \& Joachimiak, A. (2003). Crystal structure of Enterococcus faecalis SlyA-like transcriptional factor. J Biol Chem 278, 20240-20244.

Wyborn, N. R., Stapleton, M. R., Norte, V. A., Roberts, R. E., Grafton, J. \& Green, J. (2004). Regulation of Escherichia coli hemolysin E expression by H-NS and Salmonella SlyA. J Bacteriol 186, 1620-1628.

Yu, X. J., Ruiz-Albert, J., Unsworth, K. E., Garvis, S., Liu, M. \& Holden, D. W. (2002). SpiC is required for secretion of Salmonella Pathogenicity Island 2 type III secretion system proteins. Cell Microbiol 4, 531-540.

Zaharik, M. L., Vallance, B. A., Puente, J. L., Gros, P. \& Finlay, B. B. (2002). Host-pathogen interactions: host resistance factor Nramp1 up-regulates the expression of Salmonella pathogenicity island-2 virulence genes. Proc Natl Acad Sci U S A 99, 15705-15710.

Edited by: G. Dunny 